\title{
Short term outcomes in Indian patients with high risk prostate cancer after laparoscopic radical prostatectomy- data from a single institute
}

\author{
Prashant Patel ${ }^{1}$, Shrenik J Shah ${ }^{2}$ and Arpan Choudhary ${ }^{1}$
}

Cite this article: Patel P, Shah SJ, Choudhary A: Short Term Outcomes in Indian Patients with High Risk Prostate Cancer after Laparoscopic Radical Prostatectomy- Data from a Single Institute. Ann Urol Oncol 2020; 3(2): 61-70. https:// doi.org/10.32948/auo.2020.09.29

\begin{abstract}
Background Management of high risk prostate cancer (HRPC) is in evolving stage. Effectiveness of the various treatment strategies is being explored. We examined the short term efficacy of laparoscopic radical prostatectomy (LRP) in treatment of patients with HRPC. Methods Retrospective observational study had 140 HRPC patients of Indian origin, based on D'Amico classification system. Baseline workup was completed. Perioperative parameters and pathological findings were recorded. Multivariate analysis was performed to find predictive factors of pathological stage and PSM. 5 year biochemical recurrence free survival (BCRFS), cancer specific survival (CSS) and overall survival (OS) were calculated.

Results Mean age and PSA were $67.24 \pm 7.37$ years and $23.29 \mathrm{ng} / \mathrm{ml}$ respectively. Three fourth of patients had a biopsy GS $\geq 8.53 .6 \%$ of patients were of clinical stage (CS) $\leq T 2$; while $46.4 \%$ were of stage $\geq T 3$. Conversion to open surgery rate was $15 \%$. Mean operative time was 210 minutes; blood loss $230 \mathrm{ml}$; hospital stay 3 days; catheterization time 14 days; grade II or more complication rate $22.1 \%$; LN positivity $20.0 \%$; PSM rate $25.7 \%$; upstaging $35.7 \%$; down-staging 14.3\%; pT2 31.4\%; pT3a 26.4\%; pT3b 42.2\%. GS and CS were predictive of pathological stage and PSM respectively. $89.3 \%$ of cases were continent postoperatively. 5 year BCRFS, CSS and OS were $68.3 \%, 89.2 \%$ and $78.7 \%$ respectively.

Conclusions LRP is feasible and effective initial treatment for HRPC. Perioperative morbidity is acceptable. Accurate staging helps in better planning of the adjuvant therapy. Good short term survival can be achieved with multimodal therapy.
\end{abstract}

Key words High risk prostate cancer, laparoscopic radical prostatectomy, biochemical recurrence, survival

\footnotetext{
1. Department of Urology, Super specialty Hospital NSCB Medical College, Madhya Pradesh Medical Science University, Jabalpur 482003, India. 2. Department of Urology, B.J. Medical College and Civil Hospital, Gujarat University, Ahmedabad 380016, India.

Correspondence: Arpan Choudhary (Department of Urology, Super specialty Hospital NSCB Medical College, Madhya Pradesh Medical Science University, Jabalpur 482003, India; Email: jn_rpn@yahoo.co.in).
} 


\section{Introduction}

Prostate cancer $(\mathrm{PCa})$ is the second commonest cause of death in men [1]. In India, high-risk prostate cancer (HRPC) constitutes a major part of the organ confined cancer of the prostate. However, in the western countries, there has been a stage migration in the incidence toward low stage prostate cancer [2]. This difference is mainly due to the lack of uniform serum prostate specific antigen (PSA) screening in India. D'Amico had defined the HRPC as, the one having stage equal to or greater than clinically $\mathrm{T} 2 \mathrm{c}$ or a preoperative PSA $>20 \mathrm{ng} / \mathrm{ml}$ or a biopsy gleason score (GS) between 8 to 10 .

HRPC is characterized by a higher rate of metastasis and cancerrelated death than other groups [3]. Traditionally hormone therapy (HT) in combination with the radiotherapy (RT) has been used in localized high-risk prostate cancer [4]. However, it is not clear whether this approach translates into absolute benefit over the radical prostatectomy (RP). Further, there has been a considerable interest in the selection of RP as an initial therapy in selected high risk patients $[5,6]$.

RP has shown excellent long-term outcomes in the HRPC patients and these patients also have the most to gain from the treatment delivered with a curative intent [7]. Minimal access surgery in the form of either pure Laparoscopic radical prostatectomy (LRP) or robot-assisted laparoscopic RP (RARP), is now becoming a established approach with mature results [8]. Encouraged by these reports, we retrospectively analyzed our data of high-risk prostate cancer patients treated by LRP. We also tried to focus on the factors associated with poor pathological outcome.

\section{Materials and methods}

\section{Study population}

This retrospective observational study was conducted in a teaching institute in India, from 2015 to 2018. Approval was taken from institutional ethical committee. The study was performed in accordance with the Declaration of Helsinki. Patients gave their informed consent for their participation. Data of all patients of $\mathrm{PCa}$ treated in the hospital from 2003 to 2018 was collected. Patients were screened by serum PSA, clinical staging and GS of prostate biopsy. Cases of HRPC were identified as per following inclusion criteria: 1) PSA $\geq 20 \mathrm{ng} / \mathrm{ml}$ or Gleason Score $8-10$ or clinical stage $\geq \mathrm{T} 2 \mathrm{c}$; 2) No evidence of metastatic disease on bone scan or CT scan or MRI; 3) Patients fit for surgery. Exclusion criteria were as follows: 1) Patient with the life expectancy of less than 10 years; 2) Patient unfit or not willing for surgery; 3) Patients received neoadjuvant therapy.

\section{Management protocol}

All included fit patients underwent complete preoperative work up including CT/MRI, isotope bone scan, and continence assessment. Transperitoneal LRP with standard bilateral pelvic lymph node dissection was performed. Procedures were performed or supervised by a single surgeon. A five-port access was made for laparoscopy. Removal of all nodal tissue medial to the external iliac vein and the obturator fossa was completed, followed by removal of the prostate. A Non-nerve sparing procedure was completed. Operative parameters such as blood loss, operative time and any other intra-operative event were recorded. Complications were reported as per Clavien-Dindo classification (CDC) system.

Routine postoperative care was given. Patients were mobilized on the same day at evening and chest physiotherapy was started. Gradual oral feeding was given from the next day morning. The drain was removed, when output was below $50 \mathrm{ml}$. Patients were discharged with per urethral catheter. Pericatheterogram was performed on the 14th postoperative day. If anastomosis was found intact, per urethral catheter was removed. Otherwise per urethral catheter was continued for another week and removed only after insuring the integrity of the anastomosis radiographically. Final time of catheter removal and any early and late complications were recorded by CDC grades. Postoperative adjuvant hormonal treatment was given to the cases with seminal vesicle (pT3b) or lymph node involvement. It was given in the form of Injection Triptorelin, $11.25 \mathrm{mg}$, once and Tablet Bicalutamide, $50 \mathrm{mg}$,

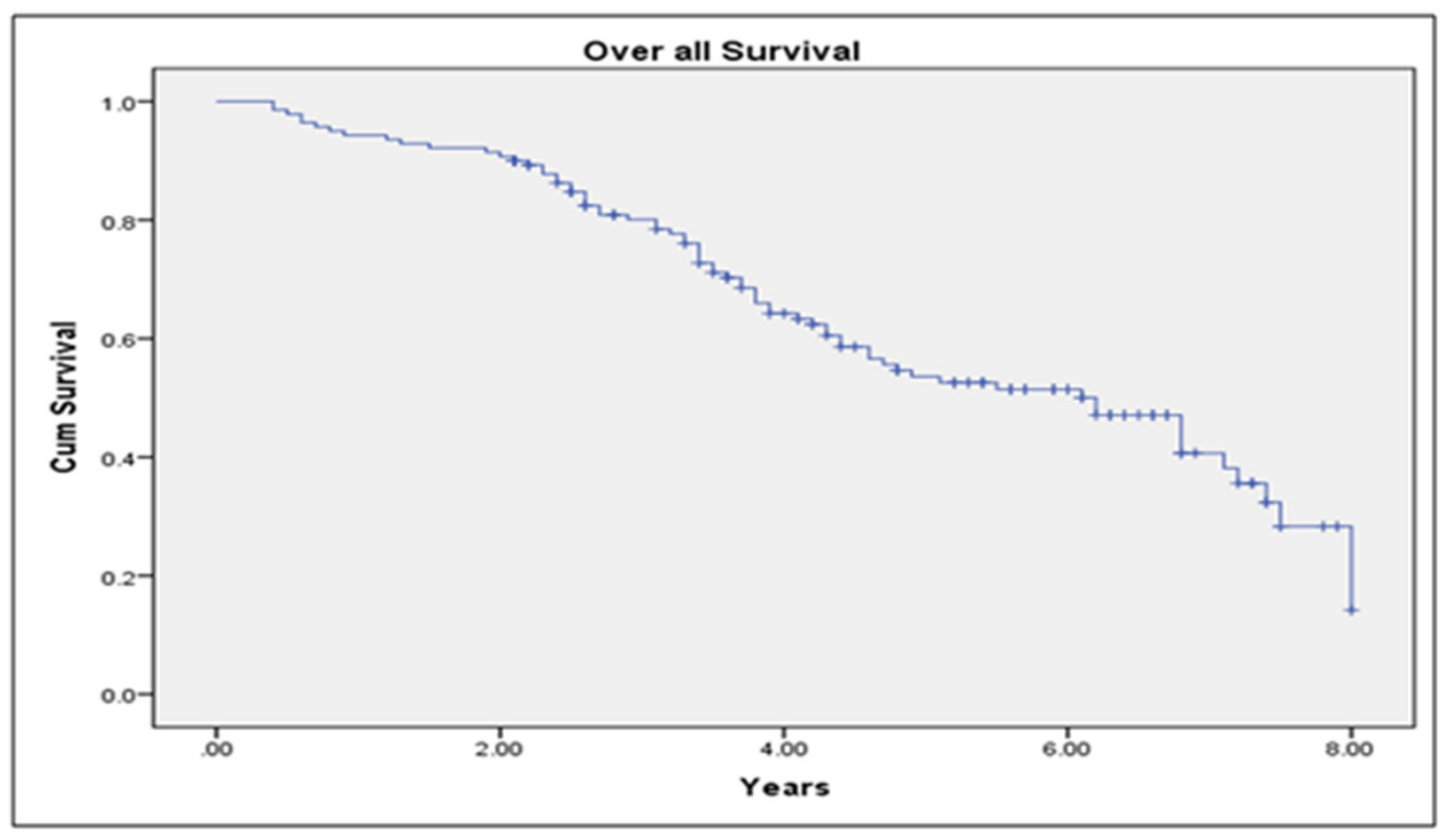

Figure 1. Kaplan-Meier curve showing 10 years overall survival of study patients. 
Table 1. Baseline clinical and demographical data of study participants.

\begin{tabular}{|c|c|}
\hline Study variables & Frequency $(n=140)$ \\
\hline Age (years) & $67.24 \pm 7.37(50-82)$ \\
\hline \multicolumn{2}{|l|}{ Symptoms, n (\%) } \\
\hline Obstructive & $74(52.8 \%)$ \\
\hline Irritative & $27(19.2 \%)$ \\
\hline Asymptomatic & $25(17.8 \%)$ \\
\hline Obstructive and Irritative & $6(4.2 \%)$ \\
\hline Hematuria & $4(2.8 \%)$ \\
\hline Retention & $4(2.8 \%)$ \\
\hline \multicolumn{2}{|l|}{ Serum PSA* (ng/ml) } \\
\hline$<4$ & $9(6.4 \%)$ \\
\hline $4-10$ & $16(11.4 \%)$ \\
\hline $11-20$ & $34(24.3 \%)$ \\
\hline$>20$ & $81(57.9 \%)$ \\
\hline \multicolumn{2}{|l|}{ Clinical stage, n (\%) } \\
\hline cT1 & $16(11.4 \%)$ \\
\hline cT2 & $59(42.2 \%)$ \\
\hline cT3 & $57(40.7 \%)$ \\
\hline cT4 & $8(5.7 \%)$ \\
\hline \multicolumn{2}{|l|}{ Gleason score, n (\%) } \\
\hline 7 & $34(24.3 \%)$ \\
\hline 8 & $46(32.8 \%)$ \\
\hline 9 & $45(32.2 \%)$ \\
\hline 10 & $15(10.7 \%)$ \\
\hline \multicolumn{2}{|l|}{ Co-morbidities, n (\%) } \\
\hline Hypertension & $78(55.7 \%)$ \\
\hline Diabetes & $32(22.8 \%)$ \\
\hline Pulmonary disease & $21(15.0 \%)$ \\
\hline Cardiac disease & $20(14.2 \%)$ \\
\hline Neurological disease & $10(7.1 \%)$ \\
\hline Chronic kidney disease & $5(3.6 \%)$ \\
\hline
\end{tabular}

* Prostate specific antigen.

OD for 3 months; while adjuvant radiotherapy was preferred in patients with PSM. Postoperatively, patients were followed with serum PSA and DRE every 3 monthly for 2 years and later every 6 monthly until 5 years and then annually thereafter.

\section{Outcome Assessment and Analysis}

All operated patients were evaluated for any biochemical recurrence (BCR). It was defined as the serum PSA levels $>0.2 \mathrm{ng}$ / $\mathrm{ml}$ from the nadir value on two occasions at a 3-month interval. These patients were subjected to a local imaging such as CT scan or MRI and Bone scan. Further treatment, i.e. salvage radiation or hormone therapy, was deferred until documented relapse occurred (as seen by imaging or biopsy). Patients who progressed while on hormonal therapy were given additional chemotherapy. All operated patients were evaluated for urinary continence. Continence was defined as freedom from the use of any form of protection (pad or cloth). Potency was not assessed at follow up, as a nerve sparing approach was chosen.

Clinical data were presented in the form of mean, median, range, percentage and standard deviation. Kaplan-Meier plots were used to graphically explore the BCR-free survival as well as CSS and overall survival (OS) rates. Moreover, the univariate and multivariate analysis were performed to find the association between clinical factors and final pathological findings. All analysis was done with the help of SPSS, IBM software, version 21.0. Confidence interval was set at $95 \%$ and statistical significance was kept below 0.05 .

\section{Results}

Baseline Characteristics

$48.0 \%$ of the patients were 61 to 70 years old (Table 1). 74 patients had symptoms of urinary retention at diagnosis. Median serum PSA was $23.29 \mathrm{ng} / \mathrm{ml}$. A value of $>20 \mathrm{ng} / \mathrm{ml}$ was found in 81 patients (57.8\%). Around half of the patients were in clinical stage T1/T2. Three fourth of the patients had a biopsy GS between 8 to 10. Hypertension and diabetes were the major co-morbidities.

\section{Perioperative Parameters and Pathological Finding}

Conversion to open surgery had to be done in 21 patients. Mean operating time was 210 minutes and average blood loss was 230 $\mathrm{ml}$ (Table 2). The average postoperative stay was 3 nights and median catheterization time was 14 days in the study. Eighteen cases required blood transfusion in the postoperative period. Overall morbidity due to complications was seen in 44 (31.4\%) patients. Out of these, CDC grade I and II complications were seen in 34 patients. Ten cases had grade III complications. 
Table 2. Perioperative parameters of patients underwent LRP for high risk localized prostate cancer.

\begin{tabular}{|c|c|}
\hline Parameter & Findings \\
\hline Conversion to open surgery, $\mathrm{n}(\%)$ & $21 / 140(15.0 \%)$ \\
\hline Operating time, min (mean) & 210 \\
\hline Blood loss, mL (mean) & 230 \\
\hline Postoperative hospitalization, nights (mean) & 3 \\
\hline Catheterization time, days (median) & 14 \\
\hline \multicolumn{2}{|l|}{ Complications* (Management) } \\
\hline Wound infection (conservative) & $5(3.6 \%)$ \\
\hline Hemorrhage, hematoma (no transfusion) & $5(3.6 \%)$ \\
\hline Obturator nerve neuropraxia (conservative) & $3(2.1 \%)$ \\
\hline Hemorrhage (transfusion) & $18(12.9 \%)$ \\
\hline Urinary tract infection (antibiotics) & $3(2.1 \%)$ \\
\hline Bladder neck stenosis (dilatation) & $3(2.1 \%)$ \\
\hline Lymphocele (percutaneous drainage) & $2(1.4 \%)$ \\
\hline \multirow[b]{2}{*}{ Ureteric orifice diathermy (DJ stent inserted) } & $4(2.9 \%)$ \\
\hline & $1(0.7 \%)$ \\
\hline
\end{tabular}

*As per Clavien-Dindo classification.

Local staging in the final pathology revealed pT3 in $68.6 \%$ of the patients (Table 3). Gleason score of more than 7 was found in $82.1 \%$ of patients. A median of 16 lymph nodes (range 10-21) were removed by lymphadenectomy. Twenty percent of patients had positive pelvic lymph nodes. 36 patients had positive surgical margins. Down-staging of tumor was seen in 20 cases, while upstaging was observed in 50 cases. Adjuvant RT was delivered to $25.7 \%$ of patients; while adjuvant HT was administered in $57.9 \%$ of patients.

\section{Outcome and Prognostic Factors}

Median follow up period was 82 months. BCR-free survival at 5 years after LRP was $68.3 \%$; CSS at 5 years was $89.2 \%$ and OS at 5 years was $78.7 \%$ (Figure 1-3). $89.3 \%$ of the patients were continent after 1 year of follow up. On multivariate analysis, only GS of prostate biopsy was found to be predictive of final pathological staging $(\mathrm{p}=0.02)$ (Table 4). While for prediction of positive surgical margins, clinical stage showed the better correlations $(\mathrm{p}=0.03)$.

\section{Discussion}

Encouraged from the results of RP in localized disease, RP is now being utilized with greater frequency in high risk disease also [9]. Many authors have reported a decent short and long term results in HRPC, treated with RP as a part of multimodal therapy $[10,11]$. Few studies have even shown the superiority of RP over
RT for HRPC $[12,13]$. RP in this context not only provides the accurate pathological staging, it also helps in earlier detection of the recurrence and better planning of additional adjuvant therapy. Chronological age was not an exclusion criterion in our study, as we have performed LRP in the patients as old as 82 years. Nagao $\mathrm{K}$ et al. operated on patient's even up to 86 years of age in their series of HRPC [14]. As long as the patient is fit and is having the life expectancy of at least 10 years, he can be taken for RP.

PSA distribution among the various other studies of HRPC treatment by RP was not uniform (Table 5). Mean PSA around $10 \mathrm{ng} / \mathrm{ml}$ was found in a few studies $[7,10,14,15,16,17]$ while a value between $15-25 \mathrm{ng} / \mathrm{ml}$ was observed in others, including in our study $[5,11,18,19]$. Similarly the distribution of biopsy GS was variable. A score below 8 in more than half of the cases was reported by few authors [11, 14, 16, 18, 19]; while a score of 8 or more was noted by others, including us $[5,10,17]$. However, patient's clinical stage in our study was similar to the other reports. Conversion to open surgery had to be done in $15 \%$ of our cases. Brassetti A et al. in his research on worldwide LRP over 20 years found a declining trend in conversion rate, as the surgeons experience increases [20]. A conversion rate of up to $10 \%$ was stated in initial 40 cases, followed by a sharp decrease. Our high conversion rate was also probably due to the difficulties encountered in the initial cases, especially in HRPC. Other perioperative parameters such as the amount of blood loss and hospital stay were comparable to the studies in the literature $[15$, 18]. However, operative time was increased in our study (210 min) as compared to the time reported by Shao $\mathrm{P}$ et al. (134 min) and 
Table 3. Clinical and pathological outcomes of high risk prostate cancer patients, treated by LRP.

\begin{tabular}{ll}
\hline Study variables & Frequency $(\mathbf{n}=\mathbf{1 4 0})$ \\
\hline & \\
Pathological Stage, $n(\%)$ & $44(31.4 \%)$ \\
pT2 & $37(26.4 \%)$ \\
pT3a & $59(42.2 \%)$ \\
pT3b & \\
Postoperative Gleason Score, $n(\%)$ & $25(17.9 \%)$ \\
7 & $44(31.4 \%)$ \\
8 & $54(38.6 \%)$ \\
9 & $17(12.1 \%)$ \\
10 & $36(25.7 \%)$ \\
Surgical margin, $n(\%)$ & $104(74.3 \%)$ \\
Positive & \\
Negative & $28(20 \%)$ \\
Lymph node status, $n(\%)$ & $112(80 \%)$ \\
pN1 & \\
pN0 & $125(89.3 \%)$ \\
Postoperative urinary continence, $n(\%)$ & $15(10.7 \%)$ \\
Yes & \\
No &
\end{tabular}

Benedetto A et al. (180 min) [15, 18]. Catheterization time of 14 days was similar in our study and the study of Benedetto A et al. [15]. While Shao $P$ et al. removed the catheter at 7 th day [18].

We found an overall complication rate of $31.4 \%$ as per CDC system. Despite a high rate, around one third was of grade I. Our blood transfusion rate $(12.9 \%)$ was similar to the rate reported by Varca V et al. (11.8\%) [11]. Grade IIIa and IIIb complications occurred in $3.5 \%$ and $3.6 \%$ of the cases in our study, respectively; which were comparable to the findings of Varca $\mathrm{V}$ et al. $(1.0 \%$ \& $1.4 \%)$, Benedetto A et al. $(2.5 \% \& 4.0)$ and Bijalwan $\mathrm{P}$ et al. $(2.7 \% \& 1.8 \%)[11,15,19]$. We didn't encounter any grade IV complication. Postoperative urinary continence in terms of no pad use was observed in $89.3 \%$ of our patients after 12 months. Varca $\mathrm{V}$ et al. and Bijalwan $\mathrm{P}$ et al reported a slightly lower continence rate of $81.8 \%$ and $79.8 \%$, respectively $[11,19]$; while Benedetto A et al. found the similar outcome (91.8\%) [15]. As we performed a non-nerve sparing approach, the postoperative potency rate was not assessed. Varca V et al. also supported this approach in HRPC patients [11]. However, recently many authors have shown the feasibility of nerve-sparing approach in HRPC with the decent potency rate [15].

More than two third (68.6\%) of our patients had T3 pathological stage, unlike the near equal representation of pT2 and pT3 in other reports [5, 15, 19, 17] (Table 5). Specimen GS of our patients was also higher ( $\geq 8-82.1 \%$ ) compared to the other similar reports. These have probably been the reasons for a high lymph node positivity rate $(20.0 \%)$ in our study. While a rate ranging from $1.6 \%$ to $25.0 \%$ was reported by others. Down-staging and upstaging of the tumor was observed in $14.3 \%$ and $35.7 \%$ of our patients respectively. A similar trend was also revealed by Benedetto $\mathrm{AD}$ et al [15], with

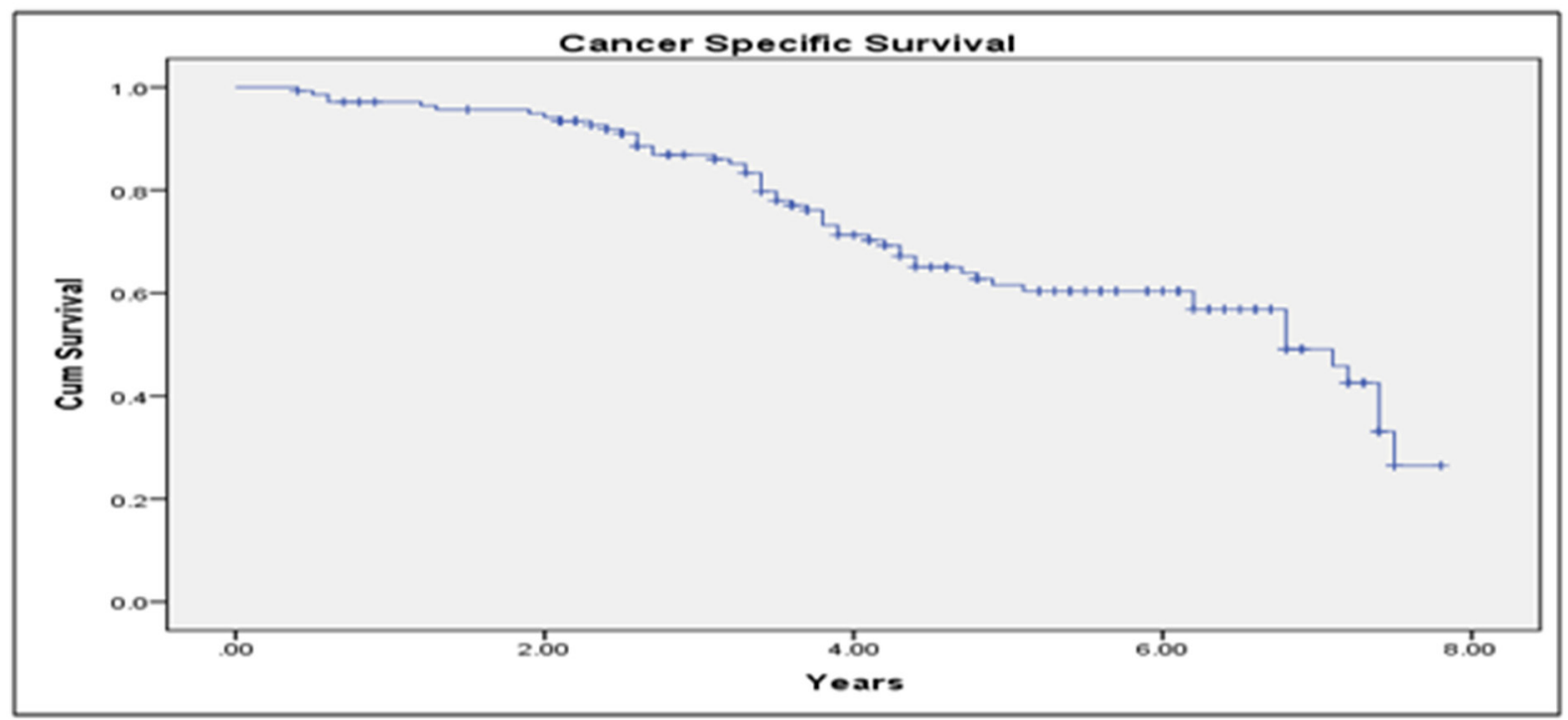

Figure 2. Kaplan-Meier curve showing 10 years cancer specific survival of study patients. 
Table 4. Correlation between Clinical factors and the final pathological findings.

\begin{tabular}{|c|c|c|c|c|}
\hline & PSA Score & $\begin{array}{l}\text { pT2 } \\
(n=44)\end{array}$ & $\begin{array}{l}\text { pT3b } \\
(n=59)\end{array}$ & p Value \\
\hline \multirow{12}{*}{$\begin{array}{l}\text { Pathological } \\
\text { Stage }\end{array}$} & $<4$ & 5 & 2 & \multirow{5}{*}{0.15} \\
\hline & $4-10$ & 6 & 7 & \\
\hline & $11-20$ & 12 & 13 & \\
\hline & $>20$ & 21 & 37 & \\
\hline & \multicolumn{3}{|c|}{ Clinical Stage } & \\
\hline & $\mathrm{cT} 1$ & 5 & 6 & \multirow{5}{*}{0.05} \\
\hline & $\mathrm{cT} 2$ & 25 & 16 & \\
\hline & cT3 & 12 & 33 & \\
\hline & cT4 & 2 & 4 & \\
\hline & \multicolumn{3}{|l|}{ GS Score } & \\
\hline & 7 & 9 & 10 & \multirow[b]{2}{*}{0.02} \\
\hline & $8-10$ & 35 & 49 & \\
\hline
\end{tabular}

Table 4. Correlation between Clinical factors and the final pathological findings (Continued).

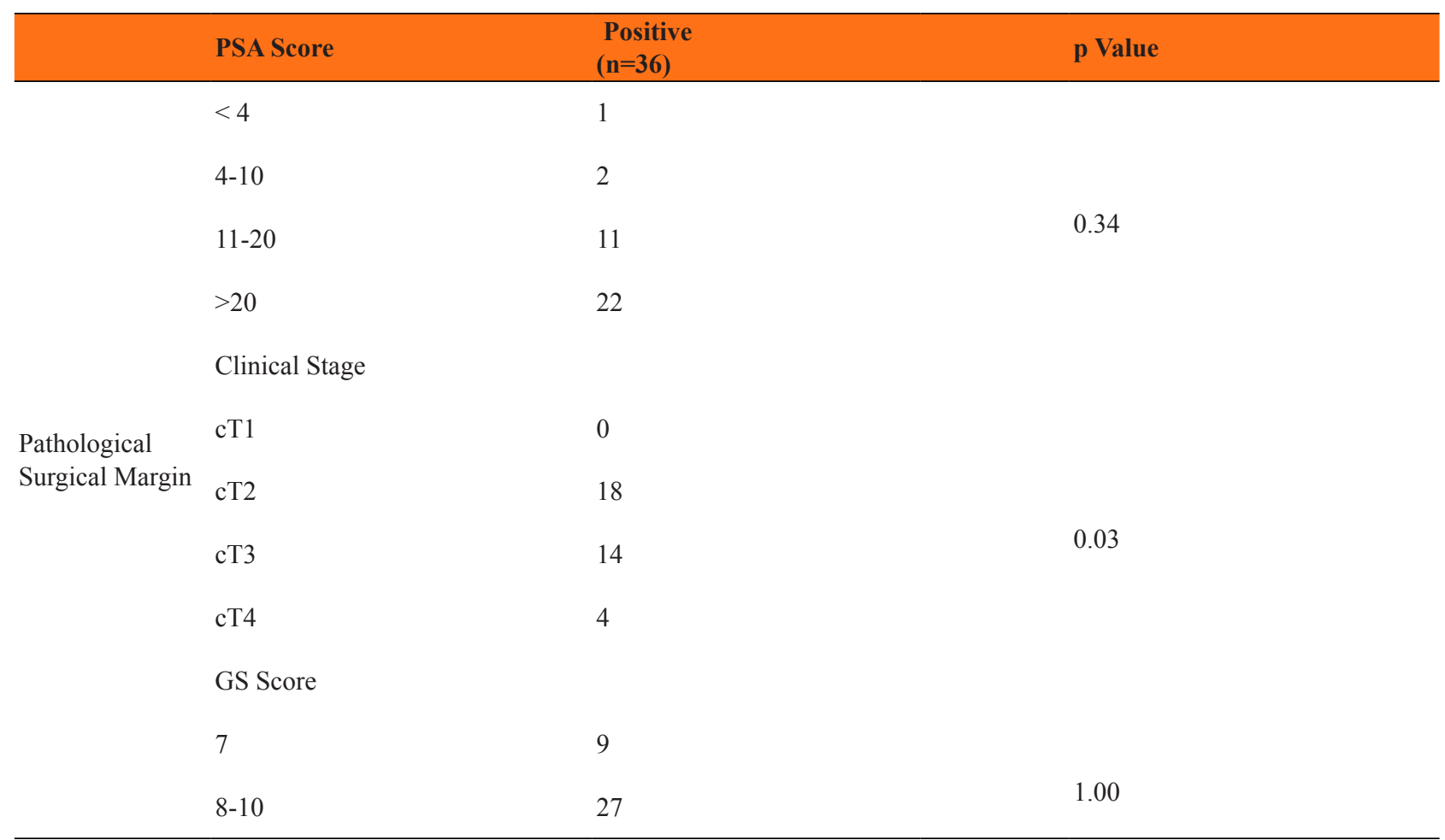

down-staging in $6.4 \%$ and upstaging in $24.7 \%$ of the patients. The rate of PSM in our study (25.7\%) was comparable to the findings of other studies (range 23.1\%-50.5\%) (Table 5). We found the clinical stage to be a good predictor of PSM. Kang SG also found clinical stage along with the percentage of tumor in the specimen, to be the significant predictive factors [17]. Bijalwan $\mathrm{P}$ et al. found a rise in the PSM rate with an increase in the number of risk factors present (cT2c-T3b, PSA $>20 \mathrm{ng} / \mathrm{ml}$, and GS >7) [19]. We also found the biopsy GS to be a significant predictor of final pathological stage. Bijalwan $P$ et al. noted increase in the adverse pathological features with a number of risk factors involved [19].

Adjuvant therapy was administered in total $83.6 \%$ of our patients. 
RT was delivered in the form of EBRT to patients with PSM. HT was given in patients with positive $\mathrm{LN}$, seminal vesicle invasion. Varca $\mathrm{V}$ et al. and Di Benedetto A et al. also found a positive effect of adjuvant therapy on survival rate in HRPC patients [11, 15]. Whereas, Furukawa $J$ et al. stated one reason for negative prognostic outcome in his series to non-utilization of any adjuvant treatment [5]. Our patient's BCRFS and CSS after 5 years were $68.3 \%$ and $89.2 \%$ respectively. Only few studies have reported a long term outcome (Table 5). Aguilera A et al. and Varca V et al. also presented the results of long term follow up [7, 11]. They found BCRFS of $62.7 \%$ and $66.2 \%$ after a median follow up of 84 and 74 months respectively. A recent systemic review by Delporte $\mathrm{G}$ et al described outcome of RP in HRPC in 42 studies and reported 5 year OS of 55.2 to $98.6 \%, 5$ year BCRFS of 40 to $94 \%$ and 5 year CSS of 89.8 to $100 \%$ [21]. Our slightly low survival rates are may be attributed to the more number of high grade and high stage tumors in study patients. Despite this, a substantial number of patients didn't develop recurrence after a median follow up of 82 months. It highlights a decent long term curability rate of HRPC by RP as a part of multimodal management. Limitations of this study are small sample size, lack of potency related outcomes and inclusion of only surgically fit HRPC patients.

\section{Conclusions}

LRP is a safe and effective procedure in HRPC patients. Perioperative morbidity is acceptable and a high continence rate can be achieved. Pathological down-staging and upstaging is observed in $14.3 \%$ and $35.7 \%$ of the cases. Lymph node positivity and PSM rates are high. Specimen GS was predictive of pathological stage, while the clinical stage was predictive of PSM. Short term BCRFS, CSS and OS can be achieved with multimodal management.

\section{Ethical policy}

Approval was taken from institutional ethical committee.
The study was performed in accordance with the Declaration of Helsinki. Patients gave their informed consent for their participation.

\section{Author contributions}

PP: Study design, data collection, manuscript editing; SJS: Study protocol, supervision, manuscript review; AC: Data analysis, manuscript revision, literature search.

\section{Competing interests}

The authors declare no competing interests.

\section{Funding}

This research did not receive any specific grant from funding agencies in the public, commercial, or not-for-profit sectors.

\section{References}

1. Jemal A, Siegel R, Ward E, Hao Y, Xu J, Thun MJ: Cancer statistics, 2009. CA Cancer J Clin 2009, 59(4): 225-249.

2. Zeigler-Johnson CM, Rennert H, Mittal RD, Jalloh M, Sachdeva R, Malkowicz SB, Mandhani A, Mittal B, Gueye SM, Rebbeck TR: Evaluation of prostate cancer characteristics in four populations worldwide. Can J Urol 2008, 15(3): 4056-4064.

3. Boorjian SA, Karnes RJ, Rangel LJ, Bergstralh EJ, Blute ML: Mayo Clinic validation of the D'amico risk group classification for predicting survival following radical prostatectomy. J Urol 2008, 179(4): 1354-60; discussion 1360-1361.

4. Meng MV, Elkin EP, Latini DM, Duchane J, Carroll PR: Treatment of patients with high risk localized prostate cancer: results from cancer of the prostate strategic urological research endeavor (CaPSURE). J Urol 2005, 173(5): 1557-1561.

5. Furukawa J, Miyake H, Inoue TA, Ogawa T, Tanaka H, Fujisawa M: Oncologic Outcome of Radical Prostatectomy as Monotherapy for

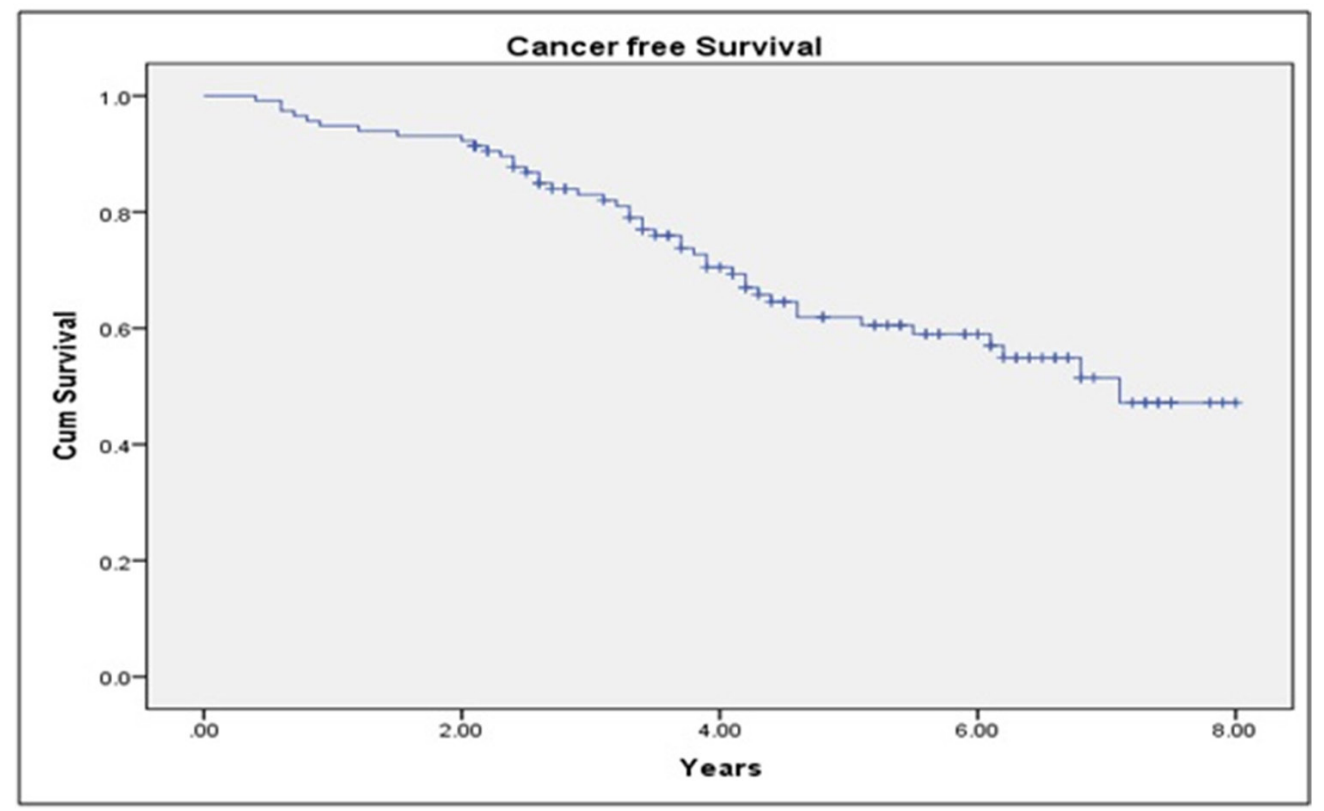

Figure 3. Kaplan-Meier curve showing 10 years biochemical recurrence free survival of study patients. 
Men with High-risk Prostate Cancer. Curr Urol 2016, 9(2): 67-72.

6. Canda AE, Balbay MD: Robotic radical prostatectomy in high-risk prostate cancer: current perspectives. Asian J Androl 2015, 17(6): 908-915; discussion 913.

7. Aguilera A, Bañuelos B, Díez J, Alonso-Dorrego JM, Cisneros J, Peña J: Biochemical recurrence risk factors in surgically treated high and very high-risk prostate tumors. Cent European J Urol 2015, 68(3): 302-307.

8. Busch J, Gonzalgo M, Leva N, Ferrari M, Friedersdorff F, Hinz S, Kempkensteffen C, Miller K, Magheli A: Propensity Score Vergleich der verschiedenen radikalen Operationstechniken beim high risk Prostatakarzinom [Propensity score comparison of the various radical surgical techniques for high-risk prostate cancer]. Aktuelle Urol 2015, 46(1): 45-51.

9. Patard PM, Roumiguié M, Prudhomme T, Doumerc N, Thoulouzan M, Gamé X, de la Taille A, Rischmann P, Soulié M, Salomon L, Beauval JB: Migration in last decade to high-risk prostate cancer after radical prostatectomy. Prog Urol 2019, 29(1): 29-35.

10. Kanehira M, Takata R, Ishii S, Ito A, Ikarashi D, Matsuura T, Kato Y, Obara W: Predictive factors for short-term biochemical recurrence-free survival after robot-assisted laparoscopic radical prostatectomy in high-risk prostate cancer patients. Int J Clin Oncol 2019, 24(9): 1099-1104.

11. Varca V, Benelli A, Perri D, Gozen AS, Fiedler M, de la Taille A, Casazza G, Salomon L, Rassweiler J, Gregori A, Gaboardi F: Laparoscopic Radical Prostatectomy in Patients with High-Risk Prostate Cancer: Feasibility and Safety. Results of a Multicentric Study. J Endourol 2018, 12; 32(9): 843-851.

12. Paterson C, Alashkham A, Lang S, Nabi G: Early oncological and functional outcomes following radical treatment of high-risk prostate cancer in men older than 70 years: A prospective longitudinal study. Urol Oncol 2016, 34(8): 335.el-7.

13. Jayadevappa R, Lee DI, Chhatre S, Guzzo TJ, Malkowicz SB: Comparative effectiveness of treatments for high-risk prostate cancer patients. Urol Oncol 2019, 37(9): 574.e11-574.e18.

14. Nagao K, Matsuyama H, Matsumoto H, Nasu T, Yamamoto M, Kamiryo Y, Baba Y, Suga A, Tei Y, Yoshihiro S, Aoki A, Shimabukuro T, Joko K, Sakano S, Takai K, Yamaguchi S, Akao J, Kitahara S; Yamaguchi Uro-Oncology Group: Identification of curable high-risk prostate cancer using radical prostatectomy alone: who are the good candidates for undergoing radical prostatectomy among patients with high-risk prostate cancer? Int J Clin Oncol 2018 , 23(4): $757-764$

15. Di Benedetto A, Soares R, Dovey Z, Bott S, McGregor RG, Eden CG: Laparoscopic radical prostatectomy for high-risk prostate cancer. BJU Int 2015, 115(5): 780-786.

16. Nyarangi-Dix JN, Görtz M, Gradinarov G, Hofer L, Schütz V, Gasch C, Radtke JP, Hohenfellner M: Retzius-sparing robot-assisted laparoscopic radical prostatectomy: functional and early oncologic results in aggressive and locally advanced prostate cancer. BMC Urol 2019, 12; 19(1): 113

17. Kang SG, Schatloff O, Haidar AM, Samavedi S, Palmer KJ, Cheon J, Patel VR: Overall rate, location, and predictive factors for positive surgical margins after robot-assisted laparoscopic radical prostatectomy for high-risk prostate cancer. Asian J Androl 2016, 18(1): 123-128.

18. Shao P, Yin C, Li J, Li P, Ju X, Lyu Q, Meng X, Hua L: [Clinical outcomes of laparoscopic radical prostatectomy for high risk prostate cancer]. Zhonghua Wai Ke Za Zhi 2015, 53(11): 847-851.

19. Bijalwan P, Pooleri GK, Kalavampara SV, Bhat S, Thomas A, Sundar P, Laddha A: Pathological outcomes and biochemical recurrencefree survival after radical prostatectomy for high-risk prostate cancer in the Indian population. Indian J Urol 2018, 34(4): 260-267.

20. Brassetti A, Bollens R: Laparoscopic radical prostatectomy in 2018 20 years of worldwide experiences, experimentations, researches and refinements. Minerva Chir 2019, 74(1): 37-53.
21. Delporte G, Henon F, Ploussard G, Briganti A, Rizk J, Rozet F, Touijer K, Ouzzane A: Radical prostatectomy for locally advanced and high-risk prostate cancer: A systematic review of the literature. Prog Urol 2018, 28(16): 875-889. 


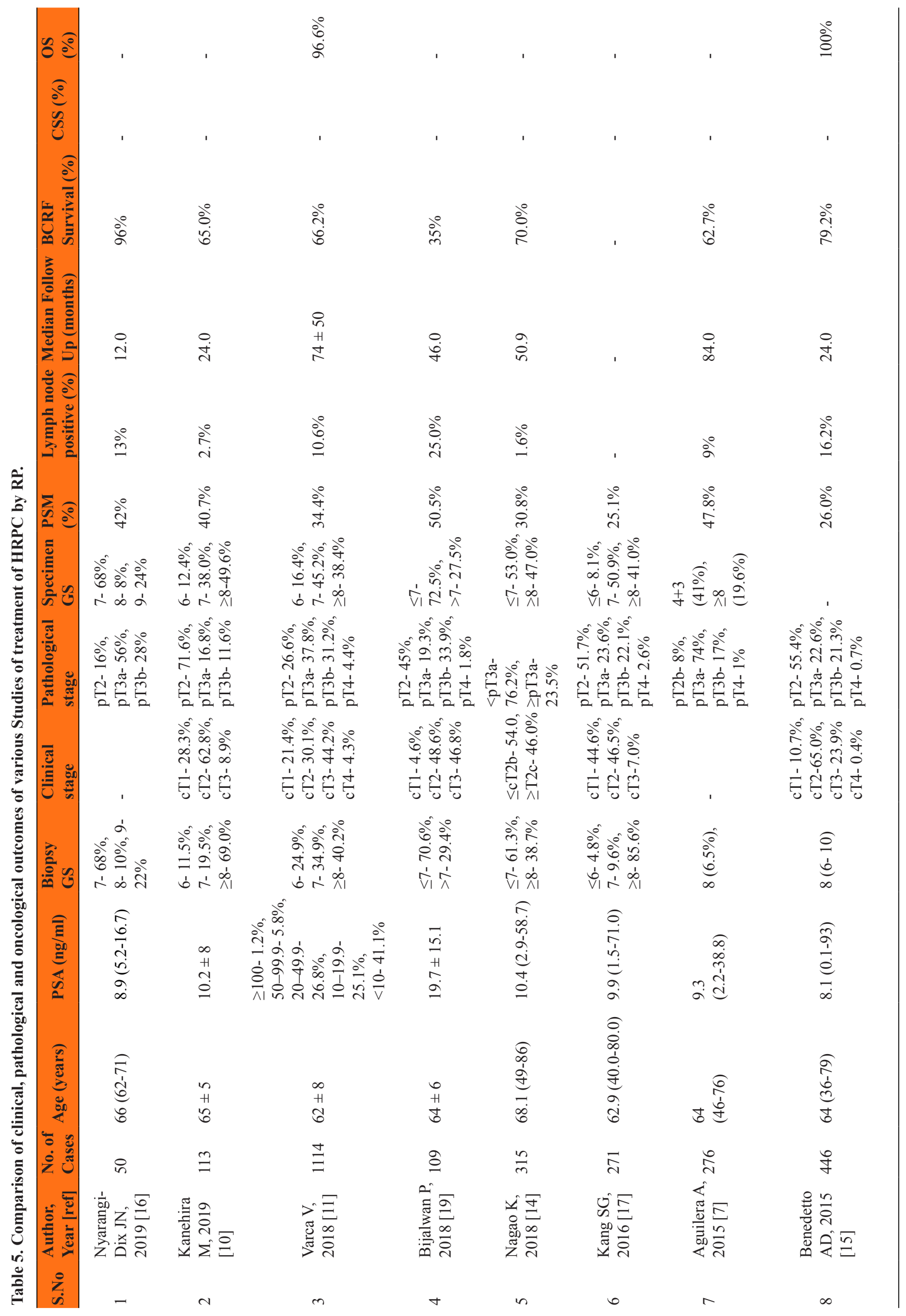




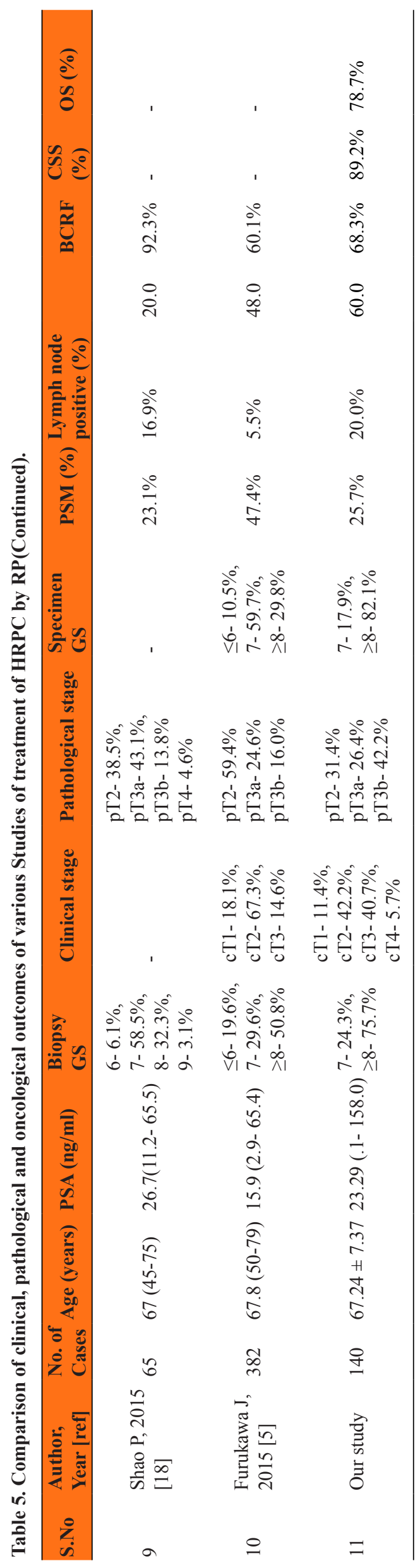

